\title{
Clinical Assessment of Sarcopenia and Changes in Body Composition During Neoadjuvant Chemotherapy for Esophageal Cancer
}

\author{
HIROSHI MIYATA ${ }^{1,2}$, KEIJIRO SUGIMURA $^{1}$, MASAAKI MOTOORI ${ }^{1}$, YOSHIYUKI FUJIWARA $^{1}$, \\ TAKESHI OMORI ${ }^{1}$, YOSHITOMO YANAGIMOTO ${ }^{1}$, MASAYUKI OHUE ${ }^{1}$, MASAYOSHI YASUI ${ }^{1}$, \\ NORIKATSU MIYOSHI ${ }^{1}$, AKIRA TOMOKUNI ${ }^{1}$, HIROFUMI AKITA ${ }^{1}$, \\ SHOGO KOBAYASHI ${ }^{1}$, HIDENORI TAKAHASHI ${ }^{1}$ and MASAHIKO YANO ${ }^{1}$ \\ ${ }^{1}$ Department of Digestive Surgery, Osaka International Cancer Institute, Osaka, Japan; \\ ${ }^{2}$ Department of Gastroenterological Surgery, Graduate School of Medicine, Osaka University, Osaka, Japan
}

\begin{abstract}
Aim: The aim of this study was to assess changes in body composition during neoadjuvant chemotherapy (NAC) and investigate whether chemotherapy-related toxicities affect body composition in patients with esophageal cancer. Patients and Methods: In ninety-four patients who underwent NAC for esophageal cancer, body composition was assessed before and after NAC. Associations between the incidence of toxicities and change in body composition during NAC were investigated. Results: Forty-four (46.8\%) and 50 (53.2\%) out of 94 patients were defined as having sarcopenia before and after $N A C$, respectively. There was no significant difference in the incidence of any toxicity pre-treatment between patients with sarcopenia and those without sarcopenia. No significant reduction in skeletal muscle mass or fat mass was observed in the patients during NAC $(p=0.501$ and $p=0.072)$. However, patients who experienced grade 4 neutropenia or febrile neutropenia during NAC showed a significantly larger decrease in change of skeletal muscle mass compared to patients who did not experience those toxicities ( $p=0.013$ and 0.036 , respectively). Conclusion: The incidence of serious adverse events such as febrile neutropenia and grade 4 neutropenia is associated with a significant reduction of skeletal muscle mass during NAC. We should make an effort to reduce the incidence of
\end{abstract}

Correspondence to: Hiroshi MIiyata, MD, Ph.D., Department of Digestive Surgery, Osaka International Cancer Institute, 3-1-69 Otemae, Chuou-ku, Osaka 541-8567, Japan. Tel: +81 669451181, Fax: +81669451900, e-mail: hmiyata@gesurg.med.osaka-u.ac.jp

Key Words: Esophageal cancer, chemotherapy, sarcopenia, body composition, toxicity, bioelectrical impedance analysis. adverse events in order to maintain an appropriate body composition during NAC.

Esophagectomy has been the mainstay of treatment for esophageal cancer for decades, but the prognosis of patients undergoing surgery alone is not favorable $(1,2)$. Therefore, neoadjuvant treatment such as neoadjuvant chemotherapy (NAC) and neoadjuvant chemoradiotherapy has been widely adopted for esophageal cancer (3-6). Neoadjuvant treatment may influence the nutritional status including body weight and body composition in patients with esophageal cancer.

Sarcopenia, which is characterized by a loss of skeletal muscle mass (SMM), has been widely studied in older people and is known to impair physical performance and survival in geriatric populations $(7,8)$. Recently, sarcopenia has received great attention in the oncology field. The presence of sarcopenia is negatively associated with treatment efficacy in patients with cancer. Sarcopenic patients with several types of cancer have been shown to be more susceptible to postoperative complications compared with non-sarcopenic patients; these complications occasionally lead to impaired overall survival (912). Pre-existing sarcopenia is associated with chemotherapyrelated toxicity and can have a negative impact on treatment efficacy and the prognosis of patients $(13,14)$. These findings imply that the body composition before chemotherapy can affect the incidence of chemotherapy-related toxicity. However, changes in body composition during chemotherapy, especially NAC, have not been fully investigated, and there are no data about how chemotherapy-related toxicities influence the body composition of patients with cancer.

In this study, we aimed to assess changes in body composition during NAC and investigate whether chemotherapy-related toxicities affect body composition in patients with esophageal cancer who underwent NAC. 


\section{Patients and Methods}

Patients. From January 2013 to August 2016, 275 patients with esophageal cancer underwent surgery at the Department of Digestive Surgery, Osaka International Cancer Institute. Among them, 123 patients received NAC for clinical stages IB, II, III or IV esophageal cancer without distant organ metastasis based on the seventh edition of the International Union Against Cancer (UICC) TNM classification (15). Of these 123 patients, 94 who underwent an assessment of body composition before and after NAC were included in this study. All patients were histologically proven for having esophageal squamous cell carcinoma. The Human Ethics Review Committees of Osaka International Cancer Institute, Osaka, Japan approved the study protocol.

Neoadjuvant chemotherapy. The NAC regimen that was used during the study period involved a combination of either 5-fluorouracil (5-FU), cisplatin, and adriamycin (ACF) or 5-FU, cisplatin, and docetaxel (DCF) (16). In the ACF regimen, 5-FU was administered at a dose of $700 \mathrm{mg} / \mathrm{m}^{2}$ via continuous intravenous infusion on days 1 through 7 , cisplatin was administered at a dose of $70 \mathrm{mg} / \mathrm{m}^{2}$, and adriamycin was administered at a dose of at $35 \mathrm{mg} / \mathrm{m}^{2}$ via rapid intravenous infusion on day 1 . In the DCF regimen, 5-FU was administered at a dose of $700 \mathrm{mg} / \mathrm{m}^{2}$ via continuous intravenous infusion on days 1 through 5 , cisplatin was administered at a dose of $70 \mathrm{mg} / \mathrm{m}^{2}$, and docetaxel was administered at a dose of $70 \mathrm{mg} / \mathrm{m}^{2}$ via rapid intravenous infusion on day 1 . In both regimens, basically, two courses of chemotherapy were used, and the courses were separated by a 3-to- 4 week interval, except when the tumor did not show any sign of significant regression after the first course of chemotherapy. All patients underwent surgery 3-6 weeks after completion of NAC.

Assessment of body composition. Body composition was assessed before NAC and 3-5 weeks after the completion of NAC with multifrequency bioelectrical impedance (BIA) with eight electrodes (InBody 720: Biospace, Tokyo, Japan). Various parameters of body composition, including SMM, body fat mass (BFM) and fat free mass (FFM) were automatically measured by InBody 720 . The normal range of SMM in each patient was shown by InBody 720 , and ranged from $90 \%$ to $110 \%$ of the standard SMM, which was calculated according to the age, gender and height of each patient $(12,17)$. In this study, sarcopenia was defined as an SMM under the lower limit of the standard SMM $(<90 \%$ of the standard). Relative change in SMM was calculated as follows: (SMM after NAC-SMM before NAC)/SMM before NAC.

Evaluation of chemotherapy-related toxicities, postoperative complications and response to chemotherapy. Toxicities were graded according to the Common Terminology Criteria for Adverse Events version 4.0 (18). Postoperative complications were defined as any complication classified as grade 3 or higher according to the Clavien Dindo classification (19).

The degree of tumor regression in surgical specimens was classified histopathologically into five categories $(20,21)$. The percentage of viable residual tumor cells within the total cancerous tissue was assessed as follows: Grade 3, no viable residual tumor cells; grade 2 , less than $1 / 3$ residual tumor cells; grade $1 \mathrm{~b}, 1 / 3-2 / 3$ residual tumor cells; grade $1 \mathrm{a}$, more than $2 / 3$ residual tumor cells; grade 0 , no significant response to chemotherapy.
Table I. Patient characteristics.

\begin{tabular}{|c|c|}
\hline Characteristic & Value \\
\hline Total number & 94 \\
\hline Age (years)* & $64.2 \pm 8.8$ \\
\hline Gender (male/female) & $76 / 18$ \\
\hline Body mass index $\left(\mathrm{kg} / \mathrm{m}^{2}\right)^{*}$ & $21.3 \pm 3.9$ \\
\hline \multicolumn{2}{|l|}{ Tumor location } \\
\hline Upper third & 12 \\
\hline Middle third & 48 \\
\hline Lower third & 34 \\
\hline \multicolumn{2}{|l|}{ Tumor depth } \\
\hline $\mathrm{cT} 1 \mathrm{~b}$ & 6 \\
\hline cT2 & 17 \\
\hline cT3 & 60 \\
\hline cT4 & 11 \\
\hline \multicolumn{2}{|l|}{ Nodal status } \\
\hline $\mathrm{cNO}$ & 18 \\
\hline $\mathrm{cN} 1$ & 46 \\
\hline $\mathrm{cN} 2-3$ & 30 \\
\hline \multicolumn{2}{|l|}{ cStage } \\
\hline IB & 5 \\
\hline II & 24 \\
\hline III & 54 \\
\hline IV & 11 \\
\hline \multicolumn{2}{|l|}{ Chemotherapy regimen } \\
\hline DCF & 88 \\
\hline $\mathrm{ACF}$ & 6 \\
\hline \multicolumn{2}{|l|}{ Cycle of neoadjuvcant chemotherapy } \\
\hline 1 & 12 \\
\hline 2 & 77 \\
\hline 3 & 5 \\
\hline \multicolumn{2}{|l|}{ Operation performed } \\
\hline Transthoracic subtotal esophagectomy & 71 \\
\hline Thoracoscopic subtotal esophagectomy & 16 \\
\hline Two-stage operation & 5 \\
\hline Exploratory thoracotomy & 2 \\
\hline
\end{tabular}

DCF: Docetaxel, cisplatin plus 5-fluorouracil (5-FU); ACF: adriamycin, cisplatin plus 5-FU. *Data are presented as the mean \pm SD.

Statistical analysis. The Chi-square test was used to compare the incidence of chemotherapy-related toxicities between the sarcopenic group and the non-sarcopenic group. A paired $t$-test was used to compare body weight and body composition before NAC and after NAC, and Student's $t$-test was used to examine the relationship between chemotherapy related-toxicity and relative change of body composition during NAC. The Mann-Whitney' $U$-test was used to examine the relationship between sarcopenia and the response to NAC. Continuous variables are expressed as the mean \pm standard deviation (SD). $p$-Values less than 0.05 were considered to indicate statistical significance. All analyses were carried out using the StatView software package version 5.0 (SAS Institute Inc., Cary, NC, USA).

\section{Results}

Patient characteristics. The characteristics of the 94 patients who were included in this study are listed in Table I. All 
Table II. Change in body composition during neoadjuvant chemotherapy (NAC).

\begin{tabular}{llccc}
\hline Measure & Pre-NAC & Post-NAC & Change during NAC & $p$-Value \\
\hline Body weight (kg) & $57.9 \pm 12.0$ & $58.0 \pm 11.9$ & $0.2 \pm 2.7$ & 0.587 \\
Skeletal muscle mass $(\mathrm{kg})$ & $25.0 \pm 4.8$ & $24.9 \pm 4.8$ & $-0.1 \pm 1.8$ & 0.501 \\
Body fat mass (kg) & $12.5 \pm 6.9$ & $12.1 \pm 6.5$ & $-0.4 \pm 1.9$ & 0.072 \\
Fat free mass (kg) & $45.4 \pm 7.8$ & $45.9 \pm 8.1$ & $0.5 \pm 2.3$ & 0.029 \\
\hline
\end{tabular}

Data are presented as the mean \pm SD.

Table III. Relationship between sarcopenia before neoadjuvant chemotherapy and chemotherapy-induced toxicity.

\begin{tabular}{lcccc}
\hline Adverse event & Grade & Sarcopenic group $(\mathrm{n}=44)$ & Non-sarcopenic group $(\mathrm{n}=50)$ & $p$-Value \\
\hline Leucopenia & $0-3$ & 27 & 39 & 11 \\
\multirow{2}{*}{ Neutropenia } & 4 & 17 & 14 & 0.078 \\
Febrile neutropenia & $0-3$ & 16 & 36 & 0.385 \\
& 4 & 28 & 21 & 0.319 \\
Diarrhea & 0 & 23 & 29 & 25 \\
\\
Stomatitis & 3 & 21 & 25 & 0.826 \\
& $0-1$ & 21 & 36 & 0.524 \\
\end{tabular}

patients received at least one cycle of cisplatin-based NAC. Tumor resection was undertaken for all patients after NAC, but two patients underwent exploratory thoracotomy because of tumor invasion to the trachea or the descending aorta.

Change in body composition during chemotherapy. Before NAC, $44(46.8 \%)$ out of the 94 patients were identified as having sarcopenia. After the completion of NAC, the number of patients with sarcopenia rose slightly to $50(53.2 \%)$ $(p=0.382)$.

There was no significant difference in body weight before and after NAC $(p=0.501$, Table II). SMM also did not significantly change during NAC.

Relationship between sarcopenia at the baseline and toxicity. Grade 4 leucopenia, grade 4 neutropenia, and febrile neutropenia were observed during NAC in $29.8 \%, 68.1 \%$ and $53.2 \%$ of patients, respectively. There was no significant difference in the incidence of these toxicities between the sarcopenic and non-sarcopenic groups at baseline $(p=0.078$, $p=0.385$, and $p=0.319$, Table III). There was no significant difference in the incidence of non-hematological toxicities such as diarrhea and stomatitis between the groups ( $p=0.826$, and $p=0.524$, Table III).
Relationship between toxicity and relative change in body composition after NAC. We investigated the relationship between chemotherapy-related toxicity and relative change in body composition during NAC to examine whether chemotherapy-related toxicity influences body composition. Patients who experienced grade 4 neutropenia or febrile neutropenia during NAC showed a significantly larger relative decrease in SMM compared to patients who did not experience such high grade toxicities ( $p=0.013$ and $p=0.036$, Table IV). Furthermore, there was significant difference in relative change in FMM between patients with grade 4 neutropenia or febrile neutropenia during NAC and those with milder toxicity ( $p=0.029$ and $p=0.046)$.

Relationship between sarcopenia and efficacy and postoperative complications. There was no significant difference in pathological response to chemotherapy in the sarcopenic and non-sarcopenic groups ( $p=0.357$, Table V). Among 92 patients who underwent subtotal esophagectomy, postoperative complications occurred in 34 (37.0\%). The incidence of pneumonitis, anastomotic leakage and infectious complications including pneumonitis, surgical site infection and empyema was $12.8 \%, 7.6 \%$ and $18.5 \%$, respectively. There was no significant difference in the incidence of any 
Table IV. Relationship between chemotherapy-induced toxicity and relative change in body composition after neoadjuvant chemotherapy.

\begin{tabular}{|c|c|c|c|c|c|c|c|c|}
\hline Adverse event & Grade & Cases & $\begin{array}{l}\text { Relative change } \\
\text { in SMM }\end{array}$ & $p$-Value & $\begin{array}{l}\text { Relative change } \\
\text { in BFM }\end{array}$ & $p$-Value & $\begin{array}{l}\text { Relative change } \\
\text { in FMM }\end{array}$ & $p$-Value \\
\hline All & & 94 & $-0.25 \pm 6.6$ & & $6.2 \pm 53.7$ & & $1.2 \pm 5.2$ & \\
\hline \multirow[t]{2}{*}{ Leucopenia } & $0-3$ & 66 & $0.6 \pm 5.5$ & 0.056 & $3.9 \pm 29.5$ & 0.531 & $1.5 \pm 4.7$ & 0.307 \\
\hline & 4 & 28 & $-2.2 \pm 8.4$ & & $11.5 \pm 88.3$ & & $0.3 \pm 6.2$ & \\
\hline \multirow[t]{2}{*}{ Neutropenia } & $0-3$ & 30 & $1.8 \pm 5.0$ & 0.036 & $1.8 \pm 19.4$ & 0.596 & $2.9 \pm 5.0$ & 0.029 \\
\hline & 4 & 64 & $-1.2 \pm 7.0$ & & $8.2 \pm 63.8$ & & $0.4 \pm 5.2$ & \\
\hline \multirow[t]{2}{*}{ Febrile neutropenia } & 0 & 44 & $1.5 \pm 4.6$ & 0.013 & $2.3 \pm 17.1$ & 0.512 & $2.3 \pm 4.6$ & 0.046 \\
\hline & 3 & 50 & $-1.8 \pm 7.7$ & & $9.6 \pm 72.1$ & & $0.2 \pm 5.5$ & \\
\hline \multirow[t]{2}{*}{ Diarrhea } & $0-1$ & 46 & $0.9 \pm 5.28$ & 0.088 & $0.9 \pm 21.1$ & 0.359 & $1.3 \pm 4.2$ & 0.889 \\
\hline & $2-4$ & 48 & $-1.4 \pm 7.6$ & & $11.2 \pm 79.3$ & & $1.1 \pm 6.1$ & \\
\hline \multirow[t]{2}{*}{ Stomatitis } & $0-1$ & 65 & $0.4 \pm 5.8$ & 0.182 & $1.0 \pm 23.2$ & 0.161 & $1.4 \pm 5.2$ & 0.581 \\
\hline & $2-4$ & 29 & $-1.6 \pm 8.1$ & & $17.8 \pm 90.0$ & & $0.4 \pm 5.3$ & \\
\hline
\end{tabular}

SMM: Skeletal muscle mass; BFM: body fat mass; FFM: fat free mass. Data are presented as the mean \pm SD.

postoperative complication between patients with sarcopenia and those without sarcopenia after NAC $(p=0.694)$. There was no significant difference in the incidence of pneumonitis, infectious complications or anastomotic leakage between the two group after NAC $(p=0.748$, $p=0.607$ and $p=0.315$ ).

\section{Discussion}

In this study, we assessed the changes in body composition during NAC, and investigated whether chemotherapyrelated toxicity could affect the body composition in patients with esophageal cancer who underwent NAC. We found a number of noteworthy findings. Firstly, sarcopenia before NAC was not associated with the incidence of chemotherapy-related toxicities. Secondly, the proportion of patients with sarcopenia did not significantly increase although approximately half of the patients (46.8\%) were sarcopenic before NAC and a significant reduction of SMM during NAC was not evident in all patients. Thirdly, however, the incidence of febrile neutropenia and grade 4 neutropenia during NAC was significantly associated with a reduction of SMM.

Our study indicates that serious toxicities during chemotherapy had a negative effect on the body composition of patients with cancer. Chemotherapy causes a wide variety of chemotherapy-related toxicities such as appetite loss, bone marrow suppression, diarrhea and stomatitis; those sideeffects can sometimes lead to dose reduction of chemotherapeutic drugs and to the discontinuation of chemotherapy. There is an increasing body of evidence that pre-treatment altered body composition is associated with the incidence of chemotherapy-related toxicities $(13,14)$. However, conversely, how chemotherapy-related toxicities
Table V. Relationship between sarcopenia and response to neoadjuvant chemotherapy.

\begin{tabular}{lccc}
\hline Response & Sarcopenic group & Non-sarcopenic group & $p$-Value \\
\hline Total & 43 & 49 & \\
Grade 0 & 2 & 1 & 0.357 \\
Grade 1a & 13 & 20 & \\
Grade 1b & 9 & 12 & \\
Grade 2 & 13 & 11 & \\
Grade 3 & 6 & 5 & \\
\hline
\end{tabular}

influence body composition of patients with cancer remains unknown. To our knowledge, this is the first report to demonstrate that the incidence of serious chemotherapyrelated toxicities is associated with significant changes in body composition such as SMM and FFM during NAC.

In this study, the proportion of sarcopenic patients remained relatively unchanged after NAC, and a significant reduction of SMM was not observed in all patients with esophageal cancer. This result is inconsistent with previous studies $(22,23)$. Yip et al. assessed the changes in body composition after NAC in 35 patients with esophageal cancer who underwent NAC; the authors evaluated computed tomography (CT) images at the level of the third lumbar vertebra (L3), and showed that the proportion of patients with sarcopenia increased from $26 \%$ to $43 \%$ after NAC (22). Awad et al. carried out a study that included 47 patients with esophageal cancer who underwent CT scan before and after NAC to assess body composition, and reported that the proportion of patients with sarcopenia significantly increased from $57 \%$ to $79 \%(p=0.046)$, and significant reduction in FMM and BFM was observed during NAC (23). In those 
previous studies, almost all patients had adenocarcinoma, in contrast to squamous cell carcinoma, as in our study. Therefore, the mean pre-NAC body mass index (BMI) in previous studies was much higher than in our study $(26.7$ and $24.6 \mathrm{~kg} / \mathrm{m}^{2}$ in previous studies $v s .21 .3 \mathrm{~kg} / \mathrm{m}^{2}$ in our study). One possible explanation for the inconsistencies between our results and previous studies is that nutritious status might be maintained in a certain number of patients because of nutritional management during NAC in our study.

Our study showed that pretreatment sarcopenia was not associated with an increased incidence of chemotherapyrelated toxicities. This result is inconsistent with a number of previous studies that examined patients with cancer other than esophageal cancer. In patients with metastatic breast cancer, sarcopenia is reported to be a significant predictor of chemotherapy-related toxicities such as diarrhea and stomatitis (13). In renal cancer and hepatocellular carcinoma, sarcopenia is associated with dose-limiting toxicities of molecular target drugs $(24,25)$, and sarcopenic patients experienced significantly more chemotherapy-related toxicities than did non-sarcopenic patients with colorectal cancer (26). In patients with esophageal cancer, the effect of pretreatment sarcopenia on the incidence of chemotherapyrelated toxicities is controversial. Tan et al. demonstrated dose-limiting toxicities in $37(41.6 \%)$ out of 89 patients who underwent NAC for esophago-gastric cancer and that sarcopenia was significantly associated with dose-limiting toxicities in multivariate analysis (27). Yip et al. demonstrated that pre-treatment sarcopenia was not associated with dose reduction of chemotherapy (22). The effect of pre-treatment sarcopenia on the incidence of chemotherapy-related toxicities may depend on the type of cancer and the chemotherapeutic regimens used.

In this study, sarcopenia before surgery was not associated with the occurrence of postoperative complications. This finding is in accordance with several previous studies. Awad et al. showed that a low FFM after NAC did not increase the duration of the postoperative hospital stay and in-hospital mortality in esophageal cancer (23). Yip et al. showed that there was no significant relationship between changes in body composition during NAC and the occurrence of postoperative complications (22). In contrastd, Ida et al. demonstrated that the reduction in SMM and FMM during NAC was larger in patients with postoperative complications than in those without (28). Reisinger et al. showed that there was no significant association between reduction of SMM and mortality in 123 patients who underwent NAC (29). These previous studies, as well as our study, had only a relatively small number of patients. Larger studies are required to determine the influence of the presence of sarcopenia and changes in body composition during neoadjuvant therapy on postoperative outcome in patients with esophageal cancer who receive neoadjuvant therapy.
The explanation for the current result, i.e. that the occurrence of febrile neutropenia was associated with an increased reduction in SMM is not entirely clear. One potential explanation is that systemic inflammation due to febrile neutropenia causes a reduction in SMM. The reduction in SMM is caused by an imbalance in protein metabolism, which is a dynamic balance between protein degradation and protein synthesis (30). The activation of inflammatory signal pathways is suggested to stimulate protein degradation in skeletal muscle (31). Several pro-inflammatory proteins, such as interleukin-6 and tumor necrosis factor- $\alpha$, play a pivotal role in the modulation of the inflammatory signaling pathway during reduction of SMM (32-34). Thus, the associations between inflammatory markers such as interleukin- 6 and tumor necrosis factor- $\alpha$ and changes in body composition during NAC should be examined in further studies.

This study has several limitations. Firstly, this study included only a relatively small number of patients from a single Institution. Secondly, we assessed the influence of change in body composition during NAC on short-term but not long-term outcomes. Whether change in body composition during NAC has a negative impact on the long-term survival of patients could be evaluated in future studies. Thirdly, we used BIA methods to assess changes in body composition, whereas many previous studies used computed tomographic imaging at the L3 level. BIA is non-invasive and quick method, and can measure whole body skeletal muscle mass $(17,35,36)$, in contrast to a cross-sectional area of muscle on one computed tomographic image. However, BIA indirectly calculates body tissue content such as total body water, FMM and SMM by measuring tissue conductivity. Therefore, BIA measurements, particularly single frequency BIA, can be influenced by abnormal hydration states such as under- or over-hydration $(37,38)$. Further studies are needed to compare BIA with other methods such as computed tomography, magnetic resonance imaging and dual-energy X-ray absorptiometry in terms of clinical relevance of the assessment of changes in body composition during NAC.

In conclusion, the present study showed that sarcopenia before NAC was not associated with the incidence of chemotherapy-related toxicities and that SMM was not markedly reduced during NAC in the entire group. However, the incidence of serious adverse events during NAC such as febrile neutropenia or grade 4 neutropenia was significantly associated with reduction in SMM and FMM. We should make an effort to reduce the incidence of serious adverse events in order to maintain an appropriate body composition during NAC.

\section{References}

1 Muller J M, Erasmi H, Stelzner M, Zieren U, and Pichlmaier H: Surgical therapy of oesophageal carcinoma. Br J Surg 77: 845857, 1990. 
2 Refaely Y and Krasna MJ: Multimodality therapy for esophageal cancer. Surg Clin N Am 82: 729-746, 2002.

3 Cunningham D, Allum WH, Stenning SP, Thompson JN, Van de Velde CJ, Nicolson M, Scarffe JH, Lofts FJ, Falk SJ, Iveson TJ, Smith DB, Langley RE, Verma M, Weeden S, Chua YJ, MAGIC Trial Participants: Perioperative chemotherapy versus surgery alone for resectable gastroesophageal cancer. N Engl J Med 355: 11-20, 2006.

4 Ando N, Kato H, Igaki H, Shinoda M, Ozawa S, Shimizu H, Nakamura T, Yabusaki H, Aoyama N, Kurita A, Ikeda K, Kanda T, Tsujinaka T, Nakamura $\mathrm{K}$ and Fukuda $\mathrm{H}$ : A randomized trial comparing postoperative adjuvant chemotherapy with cisplatin and 5-fluorouracil versus preoperative chemotherapy for localized advanced squamous cell carcinoma of the thoracic esophagus (JCOG9907). Ann Surg Oncol 19: 68-74, 2012.

5 Tepper J, Krasna MJ, Niedzwiecki D, Hollis D, Reed CE, Goldberg R, Kiel K, Willett C, Sugarbaker D and Mayer R: Phase III trial of trimodality therapy with cisplatin, fluorouracil, radiotherapy, and surgery compared with surgery alone for esophageal cancer: CALGB 9781. J Clin Oncol 26: 1086-1092, 2008.

6 van Hagen P, Hulshof MC, van Lanschot JJ, Steyerberg EW, van Berge Henegouwen MI, Wijnhoven BP, Richel DJ, Nieuwenhuijzen GA, Hospers GA, Bonenkamp JJ, Cuesta MA, Blaisse RJ, Busch OR, ten Kate FJ, Creemers GJ, Punt CJ, Plukker JT, Verheul HM, Spillenaar Bilgen EJ, van Dekken H, van der Sangen MJ, Rozema T, Biermann K, Beukema JC, Piet AH, van Rij CM, Reinders JG, Tilanus HW, van der Gaast A; CROSS Group: Preoperative chemoradiotherapy for esophageal or junctional cancer. N Engl J Med 366: 2074-2084, 2012.

7 Cruz-Jentoft AJ, Baeyens JP, Bauer JM, Boirie Y, Cederholm T, Landi F, Martin FC, Michel JP, Rolland Y, Schneider SM, Topinková E, Vandewoude M, Zamboni M; European Working Group on Sarcopenia in Older People: Sarcopenia: European consensus on definition and diagnosis: Report of the European Working Group on Sarcopenia in Older People. Age Ageing 39: 412-423, 2010.

8 Janssen I, Heymsfield SB and Ross R: Low relative skeletal muscle mass (sarcopenia) in older persons is associated with functional impairment and physical disability. J Am Geriatr Soc 50: 889-896, 2002.

9 Shachar SS, Williams GR, Muss HB and Nishijima TF: Prognostic value of sarcopenia in adults with solid tumours: A meta-analysis and systematic review. Eur J Cancer 57: 58-67, 2016.

10 Levolger S, van Vugt JL, de Bruin RW and IJzermans JN: Systematic review of sarcopenia in patients operated on for gastrointestinal and hepatopancreatobiliary malignancies. Br J Surg 102: 1448-1458, 2015.

11 Lieffers JR, Bathe OF, Fassbender K, Winget $\mathrm{M}$ and Baracos VE: Sarcopenia is associated with postoperative infection and delayed recovery from colorectal cancer resection surgery. Br J Cancer 107: 931-936, 2012.

12 Ida S, Watanabe M, Yoshida N, Baba Y, Umezaki N, Harada K, Karashima R, Imamura Y, Iwagami S and Baba H: Sarcopenia is a predictor of postoperative respiratory complications in patients with esophageal cancer. Ann Surg Oncol 22: 4432-4437, 2015.

13 Prado CM, Baracos VE, McCargar LJ, Reiman T, Mourtzakis M, Tonkin K, Mackey JR, Koski S, Pituskin E and Sawyer MB:
Sarcopenia as a determinant of chemotherapy toxicity and time to tumor progression in metastatic breast cancer patients receiving capecitabine treatment. Clin Cancer Res 15: 29202926, 2009.

14 Antoun S, Borget I and Lanoy E: Impact of sarcopenia on the prognosis and treatment toxicities in patients diagnosed with cancer. Curr Opin Support Palliat Care 7: 383-389, 2013.

15 Sobin L, Gospodarowicz $M$ and Wittekind C: TNM Classification of Malignant Tumours seventh edition. New York: Wiley, 2009.

16 Miyata H, Yamasaki M, Miyazaki Y, Takahashi T, Kurokawa Y, Nakajima K, Takiguchi S, Mori $\mathrm{M}$ and Doki Y: Clinical importance of supraclavicular lymph node metastasis after neoadjuvant chemotherapy for esophageal squamous cell carcinoma. Ann Surg 262: 280-285, 2015.

17 Kaido T, Ogawa K, Fujimoto Y, Ogura Y, Hata K, Ito T, Tomiyama K, Yagi S, Mori A and Uemoto S: Impact of sarcopenia on survival in patients undergoing living donor liver transplantation. Am J Transplant 13: 1549-1556, 2013.

18 Institute NC. Common Terminology Criteria for Adverse Events (CTCAE) version 4.0 data files 2015. Available from: http://evs.nci.nih.gov/ftp1/CTCAE/About.html.

19 Dindo D, Demartines N and Clavien PA: Classification of surgical complications: a new proposal with evaluation in a cohort of 6336 patients and results of a survey. Ann Surg 240: 205-213, 2004.

20 Japanese Society for Esophageal Diseases: Guidelines for the Clinical and Pathologic Studies on Carcinoma of the Esophagus (edtn 10). Tokyo, Japan, Kanehara Syuppan, 2007.

21 Miyata H, Yamasaki M, Takiguchi S, Nakajima K, Fujiwara Y, Konishi K, Morii E, Mori M and Doki Y: Prognostic value of endoscopic biopsy findings after induction chemoradiotherapy with and without surgery for esophageal cancer. Ann Surg 253: 279-284, 2011.

22 Yip C, Goh V, Davies A, Gossage J, Mitchell-Hay R, Hynes O, Maisey N, Ross P, Gaya A, Landau DB, Cook GJ, Griffin N and Mason R: Assessment of sarcopenia and changes in body composition after neoadjuvant chemotherapy and associations with clinical outcomes in oesophageal cancer. Eur Radiol 24: 998-1005, 2014.

23 Awad S, Tan BH, Cui H, Bhalla A, Fearon KC, Parsons SL, Catton JA and Lobo DN: Marked changes in body composition following neoadjuvant chemotherapy for oesophagogastric cancer. Clin Nutr 31: 74-77, 2012.

24 Huillard O, Mir O, Peyromaure M, Tlemsani C, Giroux J, Boudou-Rouquette P, Ropert S, Delongchamps NB, Zerbib M and Goldwasser F: Sarcopenia and body mass index predict sunitinib-induced early dose-limiting toxicities in renal cancer patients. Br J Cancer 108: 1034-1041, 2013.

25 Mir O, Coriat R, Blanchet B, Durand JP, Boudou-Rouquette P, Michels J, Ropert S, Vidal M, Pol S, Chaussade S and Goldwasser F: Sarcopenia predicts early dose-limiting toxicities and pharmacokinetics of sorafenib in patients with hepatocellular carcinoma. PLoS One 7: e37563, 2012.

26 Chemama S, Bayar MA, Lanoy E, Ammari S, Stoclin A, Goéré D, Elias D, Raynard B and Antoun S: Sarcopenia is associated with chemotherapy toxicity in patients undergoing cytoreductive surgery with hyperthermic intraperitoneal chemotherapy for peritoneal carcinomatosis from colorectal cancer. Ann Surg Oncol 23: 3891-3898, 2016. 
27 Tan BH, Brammer K, Randhawa N, Welch NT, Parsons SL, James EJ and Catton JA: Sarcopenia is associated with toxicity in patients undergoing neo-adjuvant chemotherapy for oesophago-gastric cancer. Eur J Surg Oncol 41: 333-338, 2015.

28 Ida S, Watanabe M, Karashima R, Imamura Y, Ishimoto T, Baba Y, Iwagami S, Sakamoto Y, Miyamoto Y, Yoshida N and Baba $\mathrm{H}$ : Changes in body composition secondary to neoadjuvant chemotherapy for advanced esophageal cancer are related to the occurrence of postoperative complications after esophagectomy. Ann Surg Oncol 21: 3675-3679, 2014.

29 Reisinger KW, Bosmans JW, Uittenbogaart M, Alsoumali A, Poeze M, Sosef MN and Derikx JP: Loss of skeletal muscle mass during neoadjuvant chemoradiotherapy predicts postoperative mortality in esophageal cancer surgery. Ann Surg Oncol 22: 4445-4452, 2015.

30 Kandarian SC and Jackman RW: Intracellular signaling during skeletal muscle atrophy. Muscle Nerve 33: 155-165, 2006.

31 Merritt EK, Stec MJ, Thalacker-Mercer A, Windham ST, Cross JM, Shelley DP, Craig Tuggle S, Kosek DJ, Kim JS and Bamman MM: Heightened muscle inflammation susceptibility may impair regenerative capacity in aging humans. J Appl Physiol 115: 937-948, 2013.

32 Visser M, Pahor M, Taaffe DR, Goodpaster BH, Simonsick EM, Newman AB, Nevitt $M$ and Harris TB: Relationship of interleukin-6 and tumor necrosis factor-alpha with muscle mass and muscle strength in elderly men and women: the Health ABC Study. J Gerontol A Biol Sci Med Sci 57: M326-32, 2002.

33 Ershler WB and Keller ET: Age-associated increased interleukin6 gene expression, late-life diseases, and frailty. Annu Rev Med 51: 245-270, 2000 .
34 Di Renzo L, Sarlo F, Petramala L, Iacopino L, Monteleone G, Colica C and De Lorenzo A: Association between -308 G/A TNF- $\alpha$ polymorphism and appendicular skeletal muscle mass index as a marker of sarcopenia in normal weight obese syndrome. Dis Markers 35: 615-623, 2013.

35 Erceg DN, Dieli-Conwright CM, Rossuello AE, Jensky NE, Sun $S$ and Schroeder ET: The Stayhealthy bioelectrical impedance analyzer predicts body fat in children and adults. Nutr Res 30: 297-304, 2010.

36 Jaffrin MY and Morel H: Body fluid volumes measurements by impedance: A review of bioimpedance spectroscopy (BIS) and bioimpedance analysis (BIA) methods. Med Eng Phys 30: 12571269, 2008

37 Kyle UG, Bosaeus I, De Lorenzo AD, Deurenberg P, Elia M, Gómez JM, Heitmann BL, Kent-Smith L, Melchior JC, Pirlich M, Scharfetter H, Schols AM and Pichard C; Composition of the ESPEN Working Group: Bioelectrical impedance analysis - part I: review of principles and methods. Clin Nutr 23: 1226-1243, 2004.

38 Kyle UG, Bosaeus I, De Lorenzo AD, Deurenberg P, Elia M, Manuel Gómez J, Lilienthal Heitmann B, Kent-Smith L, Melchior JC, Pirlich M, Scharfetter H, M W J Schols A and Pichard C; ESPEN: Bioelectrical impedance analysis-part II: utilization in clinical practice. Clin Nutr 23: 1430-1453, 2004.

Received April 24, 2017

Revised May 5, 2017

Accepted May 9, 2017 